Int. J. Electrochem. Sci., 14 (2019) $6759-6772$

\title{
Corrosion inhibition effect of 2-Hydroxy Phosphonoacetic Acid and Pyrophosfate on Q235 steel, Electrochemical Noise and EIS analysis
}

\author{
Chenxi Yi ${ }^{1,2, *}$ Benfeng $Z h u^{l}$ \\ ${ }^{1}$ Department of Chemistry, Zhejiang University, Hangzhou, Zhejiang 310027, China \\ ${ }^{2}$ Bureau of Inno \& Entre Town, Hangzhou Economic \& technological development area, Hangzhou, \\ Zhejiang 310000, China \\ *E-mail: yichenxi2013@163.com
}

doi: $10.20964 / 2019.07 .28$

Received: 27 February 2019 / Accepted: 27 April 2019 / Published: 10 June 2019

The inhibiting behavior of $\mathrm{K}_{4} \mathrm{P}_{2} \mathrm{O}_{7}, \mathrm{C}_{2} \mathrm{H}_{5} \mathrm{O}_{6} \mathrm{P}$ and their mixture on $\mathrm{Q} 235$ steel corroding in the simulated stratum water has been investigated by using electrochemical noise (EN) and electrochemical impedance spectroscopy (EIS) techniques. The results show that the physical adsorption of KPP onto Q235 surface at $60{ }^{\circ} \mathrm{C}$ is somewhat faster than the chemisorption of HPAA. In the re-plotted energy distribution plot, the difference of the region where the EN energy is mostly accumulated may be adopted to distinguish the chemisorption and physical adsorption of inhibitors. Finally, the variation tendency of the charge transfer resistance obtained by EIS technique is just opposite to that of fractal dimension obtained by EN technique, which may hint that the initial corrosion processes of metals can be in-situ monitored by using EN technique expediently.

Keywords: Q235 steel; corrosion; inhibiting behavior; EIS; EN.

\section{$\underline{\text { FULL TEXT }}$}

(C) 2019 The Authors. Published by ESG (www.electrochemsci.org). This article is an open access article distributed under the terms and conditions of the Creative Commons Attribution license (http://creativecommons.org/licenses/by/4.0/). 